pÿPromoting Students Interest and Motivation Towards Science Learning : the Role of Personal Needs and Motivation Orientations

\title{
Loukomies, Anni
}

2013

Loukomies , A, Pnevmatikos , D , Lavonen , J, Spyrtou , A, Byman , R , Kariotoglou , P \& pÿJuuti , K 2013 , ' Promoting Students Interest and Motivation Towards Science Learning : the Role of Personal Needs and Motivation Orientations ' , Research in Science Education , vol. 43 , no. 6 , pp. 2517-2539 . https://doi.org/10.1007/s11165-013-9370-1

http://hdl.handle.net/10138/232681

https://doi.org/10.1007/s11165-013-9370-1

acceptedVersion

Downloaded from Helda, University of Helsinki institutional repository.

This is an electronic reprint of the original article.

This reprint may differ from the original in pagination and typographic detail.

Please cite the original version. 


\title{
Promoting Students' Interest and Motivation Towards Science Learning: the Role of Personal Needs and Motivation Orientations
}

\author{
Anni Loukomies • Dimitris Pnevmatikos • \\ Jari Lavonen • Anna Spyrtou • Reijo Byman • \\ Petros Kariotoglou • Kalle Juuti
}

(C) Springer Science+Business Media Dordrecht 2013

\begin{abstract}
This study aimed to design a teaching sequence for science education that enabled lower secondary school students to enhance their motivation towards science. Further, it looked to examine the way the designed teaching sequence affected students with different motivational profiles. Industry site visits, with embodied theory-based motivational features were included as part of the designed teaching sequence. The sequence was implemented in Finland and Greece with 54 participants, 27 from each country. Quantitative data was collected using the Evaluation of Science Inquiry Activities Questionnaire, based on the Intrinsic Motivation Inventory but did not map the expected outcomes. Interviews, however, showed that students with different motivational profiles found aspects within the module that met their psychological needs as explained by Self-Determination Theory. The results offer a perspective to adolescents' psychological needs along with some insights into how students mediate the way they value an activity in the context of science education.
\end{abstract}

Keyword Motivation orientation · Psychological needs · Industry site visit · Science education $\cdot$ Self-Determination Theory

\footnotetext{
A. Loukomies $(\bowtie)$

Viikki Teacher Training School, University of Helsinki, P.O. Box 30 (Kevätkatu 2), 00014 Helsinki, Finland

e-mail: anni.loukomies@helsinki.fi

D. Pnevmatikos $\cdot$ A. Spyrtou

Department of Elementary Education, University of Western Macedonia, 3rd Km of National Road Florina-Niki, 53100 Florina, Greece

J. Lavonen · R. Byman · K. Juuti

Department of Teacher Education, University of Helsinki, P.O. Box 9 (Siltavuorenpenger 5A), 00014 Helsinki, Finland

P. Kariotoglou

Department of Nursery Education, University of Western Macedonia, 3rd Km of National Road FlorinaNiki, 53100 Florina, Greece
} 


\section{Introduction}

Students' motivation and interest in science studies has been a widely discussed concern within science education research and also in policy papers (e.g. Osborne et al. 2003; Osborne 2008; EU 2004, 2005; OECD 2008). Although students find science-related issues important in general, many of them do not choose science courses at school and do not see themselves potentially choosing a scientific career in their future (Lavonen et al. 2008; Woolnough 1996; Osborne 2008; Tytler et al. 2008). Students hold negative stereotypical and one-sided images about science-related occupations, they do not consider these occupations worth pursuing (Scherz and Oren 2006) or they are not introduced to appealing role models to follow (Lavonen et al. 2008).

In this research, the problem of students' low motivation towards science studies has been tackled by adopting a Design-Based Research approach (DBR) (for a detailed view of the approach, see for example Design-based research collective 2003 and Juuti and Lavonen 2006). This approach has been used to support the design of an industry site visit teaching sequence for science education. In the DBR, developing a pedagogical solution and scrutinising its effectiveness are intertwined throughout the whole process. Theory-based conjectures about possibilities to enhance motivation were embodied in the designed teaching sequence (Sandoval 2004). The process of embodiment means that it is specified how high-level theoretical conjectures appear concretely in the designed teaching sequence (Sandoval 2013). In the design, out-of-school industry site visits are employed, which is in line with the OECD (2008) recommendation that students should have access to realistic information about Science and Technology and careers in the field through direct contact with professionals. Tytler et al. (2010) share this view as they argue that partnerships between schools and industrial organisations are important for local level curriculum development if the aim is to have an impact on students' engagement. According to their literature review, Lavonen et al. (2008) claim that role models met during visits may be important when students are planning their future (Fig. 1).

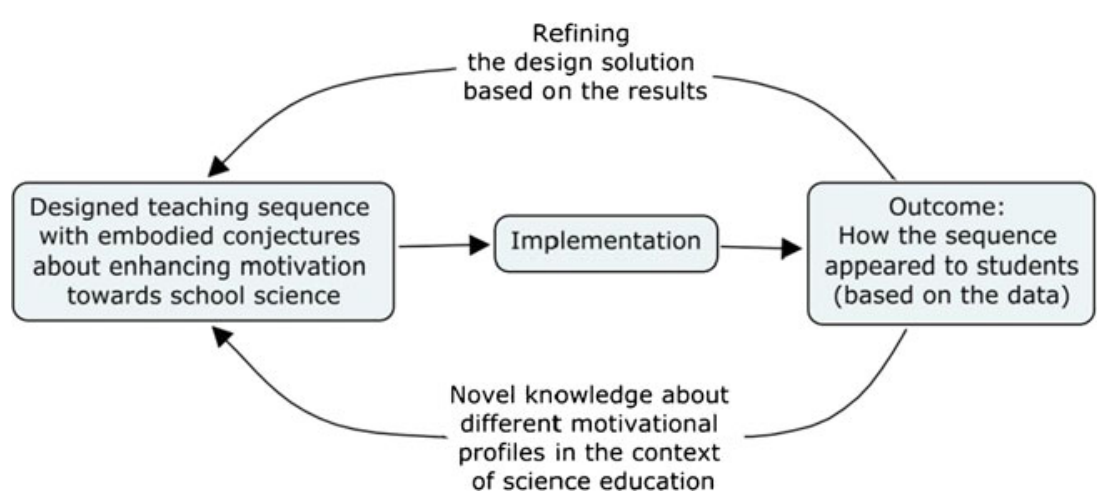

Fig. 1 Gathering novel knowledge about motivation in the context of science education and refining the design solution based on the data collected during the implementation 
Individual Differences in Motivational Orientations and the Role of Basic Psychological Needs

To conceptualise motivation, after having considered the multifaceted field of motivational science (e.g. Pintrich 2003), we decided to follow Self-Determination Theory of motivation (SDT) constructed by Edward Deci and Richard Ryan (2002). This theory takes into account the quality-based differences in students motivation orientations, which we believe in an important aspect to consider due to its implication for the classroom. Instead of examining the motivation of a whole group, it was found that consideration of how students with different motivational profiles spoke about the aspects of the teaching sequence intended to enhance their motivation, was more relevant.

The leading idea of SDT is that humans are active and growth-oriented, seeking the actualisation of their potentialities, growth and integration, fulfilling their basic psychological needs. These needs include for autonomy, competence and social relatedness, and moving their lives in desired and specific directions rather than being passive subjects to environmental forces that push them around. However, as they do not live in a vacuum, humans social environments can either facilitate or impede these inherent tendencies (Ryan and Deci 2002). The basic needs, which are assumed to be innate for all humans in spite of their cultures and across all situations, do not affect behaviour as such, but the effect is mediated by social-cognitive constructs that are more context-specific, such as the motivation orientation of a person (Deci and Ryan 2000). A person's motivation in a particular situation is a result of the interaction between immediate social context and the individual's need system that seeks fulfilment (Ryan and Deci 2002; Vansteenkiste et al. 2012). The continual interface with the social environment can either support and facilitate the natural growth process or block it by frustrating the basic psychological needs (Vansteenkiste et al. 2012). Previous experiences about fulfilment of the basic needs may affect how sensitive a certain individual is towards the aspects of teaching that aim at fulfilling the psychological needs. Individuals with different motivation orientations develop motivation towards science learning through engaging in activities that may fulfil their basic psychological needs, but different aspects of the activity appeal differently to different students. The theoretical conjectures that are embodied in this design are based on the SDT assumptions about the basic psychological needs and their relation to motivation.

One sub-theory of SDT, namely Organismic Integration Theory (OIT) is concerned with internalisation of the regulation of behaviour and values and, furthermore, the influence of the fulfilment of basic psychological needs on regulatory style and motivation orientation. Regulation of behaviour may be autonomous (self-determined) or controlled, depending on the degree of internalisation. Internalisation is not viewed in terms of a dichotomy external-internal, but rather in terms of a continuum (Ryan and Deci 2002). The OIT proposes a continuum of regulation types from non-regulation to intrinsic regulation. A certain regulatory style leads to a certain motivational orientation. Non-regulation lies on the other end of the continuum and is related to amotivation that is a state of lacking the intention to act (Ryan and Deci 2002). Amotivated students cannot find any reason to engage in a certain activity. Amotivation may result from lack of perceived competence or problems in valuing the possible outcomes of an activity, and it is the most problematic motivation orientation in the context of education. 
Controlled and ill-internalised regulatory styles, namely external and introjected regulations, are related to controlled forms of extrinsic motivation. Externally regulated behaviours are performed for the sake of some expected reward, or avoiding a threatened punishment, the underlying values of the activity are not internalised. In other words, externally regulated behaviours are conducted to satisfy an external demand or socially constructed contingency (Ryan and Deci 2002). In class settings, the need for high grades is usually the external demand that regulates students' behaviours. Introjected regulation refers to activities that are motivated by internal prods and pressures that are connected with the person's self-esteem. Introjectionbased behaviours are performed to avoid negative emotions like guilt and shame or to attain ego enhancements and feelings of worth. More autonomous forms of extrinsic motivation encompass identified and integrated regulations. Identified regulation takes place when the regulation has become a part of the self. A person consciously feels that the activity is personally important or valuable and participates in it willingly (Deci and Ryan 2000). Even though the identification of regulation in relation to a certain activity may be separated from one's other beliefs and values, compared with external and introjected regulations identified, regulation is relatively autonomous. Finally, the most self-determined form of extrinsically motivated behaviour is integrated regulation where the activity has personal importance for a valued outcome. It results when identifications have been evaluated and brought into congruence with personally endorsed values that are already part of the self. Integrated extrinsic motivation shares many qualities with intrinsic motivation. The other end of the continuum, intrinsic motivation, is a prototype of autonomous and self-determinated behaviour. Intrinsic motivation is characterised by intrinsic regulation and self-determined behaviour. Intrinsically motivated individuals engage in certain activities freely, led by the feelings of interest and enjoyment. According to Ryan and Deci (2009), "the basis of intrinsic motivation is interest" (p. 177), that is interest has close relationships to process-oriented motivational concepts such as intrinsic motivation or the experience of self-determination. Intrinsically motivated behaviours are conducted because of the inherent satisfaction of the behaviour per se, not because of any external consequences or reinforcements separable from the activity (Ryan and Deci 2002). Interest, in turn, consists of valence beliefs that feeling-related and value-related: feeling and value related (Schiefele 1999). This means that a certain activity is interesting and intrinsically motivating because it is highly valued by a person, or it generates pleasant feelings.

Along the continuum, internalisation of the regulation of behaviours increases and the motivation for certain behaviours becomes more autonomous (Ryan and Deci 2002). Students with an autonomous motivational profile (intrinsic motivation and the wellinternalised forms of extrinsic motivation) have higher grades, are more persistent in their studies, learn better, are more satisfied and experience more positive emotions towards school (Guay et al. 2008; Niemiec and Ryan 2009; Reeve and Halusic 2009). In a broader context, autonomously chosen goals are related to individuals' increased likelihood of attaining their goals and thus enhancing their well-being (Vasalampi et al. 2009). Lavigne et al. (2007) argued that science teachers' support of students' autonomy may have an impact on students' autonomous motivation towards science and even on their pursuit of working in the science-related domain.

\section{The Current Study}

The research question is:

How did students with different motivational profiles perceive the features of the designed teaching sequence that were intended to enhance their motivation? 
In order to answer the research question, we first designed a teaching sequence for science education. Conjectures about possibilities to enhance students' motivation were embodied in the design. These conjectures are related to support for the feelings of autonomy, social relatedness and competence. Secondly, we examined how students with different motivational profiles considered the intervention. This undertaking should potentially provide us with evidence to understand why the same teaching is more beneficial for the development of some students' interest and motivation but not for others. Implementing the designed teaching sequence in different contexts (i.e. in Finland and in Greece) will help us to strengthen the claims for the universality of the way the basic psychological needs guide students' engagement. This paper will focus on the affective aspects of studying science. Other papers have discussed aspects of student learning related to the designed teaching sequence implemented in the research, yet the benefits of high quality motivation for learning have been emphasised in the literature review for this paper.

\section{Method}

\section{Design}

When designing the teaching sequence, experiences gathered during several science teachers' professional development projects (Juuti et al. 2009; Lavonen et al. 2006; Lavonen et al. 2004) were utilised. The designed teaching sequence is a structured wholeness that encompasses preparation, visit and elaboration afterwards. The philosophy of inquiry-based science teaching (for details, see Minner et al. 2010) is realised through students' active participation, during the designed teaching sequence, which is related to content in materials science.

The sequence consists of the following:

Preparing phase: inquiry and classification activities for helping students to understand the science content related to the site visit, searching for information over the internet, deciding about the perspective of the report, preparing questions to the personnel of the company 2-3 hours

Site visit phase: observations, interviewing the company personnel, gathering data $2-4$ hours Processing phase: preparing articles based on the data, employing process writing technique, evaluation (approximately 3 hours)

Before the visit the students prepare themselves by searching for information on the Internet about the company they will visit, including information about the materials they use and what they produce. ICT is used here to awaken students interest in the task (Hidi and Renninger 2006). Students also prepare questions, which will be sent to the company, and plan interview questions about manufacturing processes or material science-related occupations and careers that are pursued by people at the company. Students report on their visit by writing articles about an aspect that holds interest for them. When preparing their articles, students first become acquainted with the company and its specific branch of industry through the web page of the company, then plan the perspective of their own articles and finally decide about a specific focus for their topic. Topics chosen by students may be, for example, "materials used in the production", "raw materials and their origins", "quality control", "processes in the site" or "different occupations and education needed for these occupations". In terms of learning materials science content, students conduct classification tasks to orient themselves with the topic. 
As a way of introducing students to the content that they are likely to see during their visit, the students conduct inquiry tasks related to the properties of materials. Prior to the visit, the students also familiarise themselves with the work of investigative journalists and during the visit, they utilise this knowledge to assist them to collect data (including notes of what they see and hear) and conduct short interviews with staff who have expert knowledge about the students chosen specific focus for their article. The site visit starts with an overview of the company's activities and then small groups of students are given a tour of the company's production facilities. The visit concludes with the opportunity for small groups of students to interview personnel.

After the site visit, students write articles about certain aspects of the visit in collaborative groups using a process writing technique that emphasises peer feedback. The writing process takes place within weeks, and it encompasses different phases, such as choosing the topic and perspective, compiling interview questions, conducting interviews and making notes, browsing the web in order to acquire information, writing the text and defining the language and appearance of the article. The writing task helps students organise the new knowledge they have gathered during the designed teaching sequence.

The teacher guide (54 pages) for the designed teaching sequence was written in English and used to present the aims, organisation, teaching methods and assessment methods used during the sequence. Students learning materials (47 pages) were published in order to support students' engagement and learning during the sequence. This material can be downloaded free of charge from the website http://www.edu.helsinki.fi/malu/materials/. An iterative translation technique was used to translate the designed teaching sequence and learning materials related to it from the original English version into the Greek and Finnish languages (Brislin 1986).

\section{Embodied Conjectures}

The research-based features are conjectures that are embodied in the design (Sandoval 2004). The process of embodiment means specifying how theoretical conjectures appear concretely in the design (Sandoval 2013). Research of these embodied conjectures uncovered aspects related to the effectiveness of the designed teaching sequence that helped improve it (Sandoval 2004). Besides the request of being derived from theory, a key feature to embodied conjectures is that they may lead not only to the improvement of a particular design solution but can potentially lead to refinement of a theory (Sandoval 2004, pp. 215), and, in this particular case, may generate new knowledge concerning the relationship between motivation and studying science. In other words, DBR strives to make the theoretical assumptions explicit and testable. Designing educational interventions is not simply making things and seeing if they work, but it is a theoretical activity (Sandoval 2004). In this research, the conjectures embodied in the design emerge from the SDT (e.g. Ryan and Deci 2002). It was concluded on the grounds of the reviewed literature that students' motivation may be promoted through selecting activities that support students' feeling of competency, social relatedness, autonomy and interest in science-related topics. Firstly, activities that are supposed to support students' feeling of autonomy encompass student-centred methods: students are offered choice and they actively participate in the planning of activities, with guidance about structure offered by the teacher. The intended outcome is an article with appropriate scientific content related to a particular branch of industry. Throughout the designed teaching sequence, students have plenty of decisions to make including; selecting a focus, preparing for the visit, collecting data and refining the appearance and content of their article. Even the responsibility of the organisational tasks related to the visit may be 
allocated to students where appropriate. Further, the inquiry tasks completed prior to the visit provide yet another opportunity for student to act autonomously. Structure is an important aspect here because without sufficient structure students may be lost or confused by such a multifaceted sequence. Structure makes a learning environment predictable and helps students to regulate their academic behaviours more efficiently. However, teachers should provide guidance that promotes autonomy, otherwise the structure may be experienced as controlling (Guay et al. 2008).

Secondly, support for students' feeling of social relatedness was included in the designed teaching sequence through the selection of collaborative learning activities and co-planning which help students to feel close to and trust their peers. Students' feeling of social relatedness is also supported through informal discussions between the teacher and the students. Almost all activities within the teaching sequence are conducted in collaborative groups, in which there are tasks for all group members. Students may organise the division of labour in the groups themselves. It is up to a certain teacher's knowledge about the dynamics of a certain group whether the students are allowed to conduct the division into groups themselves or whether the teacher assists with that task. Working actively with an interesting topic may enable students to get to know each other better and even to make friends.

Thirdly, support for students' feeling of competence was included in the designed teaching sequence through the selection of constructive evaluation methods, like self and group evaluation, which help students to recognise their competencies, through support for the feeling that an activity has some value or use for the student. The feeling of student competence is promoted through the process of gathering data and then using this data to write an article, and in the evaluation discussions. To support students' feeling of the value of their activities, it is highly recommended, for example, that students' articles are published somehow. The activities at the industry site are organised in a way that enables equal discussions between the students and the experts at the site. The students are responsible for their own questions; the teacher is not guiding the discussions. Throughout the whole designed teaching sequence, teacher's formative feedback should guide and redirect students' activities.

Finally, interest research suggests means of sparking students' situational interest, namely the novelty and complexity of a certain phenomenon (Silvia 2008). Students' interest is supported through offering them novel experiences, including the chance to see multifaceted, even surprising phenomena in an authentic context. Feeling-related interest is supported through selecting appealing activities, e.g. inquiry tasks and ICT activities. While valuerelated interest is supported by introducing students to the career possibilities in the field of science and technology and aspects related to technology and humans (Schiefele 1999).

The scientific content of the teaching sequence was carefully prepared in order to assist teachers to adopt the sequence into their repertoire. The designed teaching sequence supports students' learning about the nature of materials science and technology, as students become familiar with how new innovations are refined into products in authentic environments through technological processes. Students also familiarise themselves with the methods of materials science by learning how research and development concerning materials science issues is done with modelling and simulations, using high technology appliances. Moreover, students learn new materials science content, materials science terminology, physical and chemical properties of materials, and more about the production and use of materials. They become acquainted with how the behaviour of materials can be explained by analysing their structures and how microscopic models describe the properties and behaviour of materials. The structure of matter is one of the most fundamental topics in science, and a meaningful 
understanding about this topic is essential for developing a solid basis for further science studies. Therefore students should take a deep look at models, which describe the structure, properties and behaviour of materials. In relation to the designed teaching sequence used in this research, the materials science content that was introduced was: raw materials, materials, substances, phase, physical properties and chemical properties (e.g. heat conductivity, electrical conductivity), particles, monomers, thermoplastic polymers and thermosetting plastics etc. The processes that students get acquainted with are manufacturing iron from iron ore, manufacturing paper from wood and the manufacturing of different plastic qualities from raw oil. Finally, students learn about careers in material science and technology during the site visits, as they meet scientists, engineers and many types of professionals in modern materials science enterprises and laboratories. This helps them to see their possible career options from a new perspective.

\section{Participants}

Fifty-four 8th and 9th graders (mean age 14.2 years) from Finland $(n=27)$ and Greece $(n=27)$ participated in the study. Both groups came from middle class families. The two countries have different teaching traditions and outcomes on international surveys like PISA. Thus, the verification of our hypothesis in the two countries could further strengthen our hypothesis.

\section{Measurements}

The research instruments (questionnaire and interview protocol) were translated from the original English version into the Greek and Finnish language through an iterative process (Brislin 1986). The measures were translated from English to Finnish and Greek by two bilingual psychologists. Another two researchers then translated the Finnish and the Greek versions, respectively, back into English. These versions were then compared with the original and the appropriate corrections were made to the Finnish and Greek versions until all the discrepancies were eliminated.

\section{Evaluation of Science Inquiry Activities Questionnaire (ESIAQ)}

The questionnaire ESIAQ ${ }^{1}$ was employed in this research in order to track change in students' motivation towards school science, related to the designed teaching sequence. The questionnaire is based on the "Intrinsic Motivation Inventory" (IMI), a multidimensional measurement for assessing participants' subjective experience related to a target activity that has been used widely and that is internationally validated (e.g. Deci et al. 1994; Ryan 1982). The questionnaire is available from the official web site of Self-Determination Theory (www.selfdeterminationtheory.org/ questionnaires). Originally, the IMI was developed to be used in intrinsic motivation laboratory experiments in which participants have worked on an interesting activity within some experimental condition. With the IMI, their levels of interest/enjoyment, perceived competence, effort, value/usefulness, felt pressure and tension, and perceived choice while they were performing the activity are assessed.

When converting the IMI questionnaire to make it suitable for use science in education research, the questionnaire was also renamed ESIAQ. This research was not conducted in an experimental laboratory setting, and therefore it was not possible to distinguish the "activity" under scrutiny explicitly from other activities students conducted during their schooldays. In

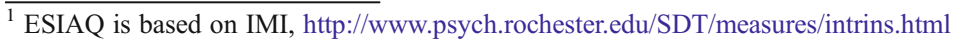


the translation, the term that was used instead of activity was "science inquiry activity". In this research, participants were tested with the ESIAQ before and after the sequence. Before the implementation of the sequence, science inquiry activity meant typical science learning activities, like practical school laboratory work. After the implementation of the sequence, science inquiry activity meant the designed teaching sequence. The students were told what was meant by the term "science inquiry activity" before and after the implementation of the designed teaching sequence. The ESIAQ uses a seven-point Likert-type scale ( $1=$ item in my case not at all true ... 7 = item in my case very true).

The instrument measured participants' interest/enjoyment (seven items), perceived competence (six items), value/usefulness (seven items), perceived choice (seven items) and relatedness (six items). Besides these, five items concerning students' effort related to the activity, and five items concerning experienced tension or pressure during the activity, were included in the questionnaire. However, it was reasoned that the subscales of perceived competence, perceived choice, relatedness, interest/enjoyment and value/usefulness cover the theory-based features that were included in the design, namely support for students' feeling of autonomy, competence, social relatedness and feeling and value-related interest, and thus subscales of effort and pressure/tension were excluded from the statistical analysis of the ESIAQ. The items within subscales were randomly ordered in the questionnaire, and the wordings of some questions were reversed.

\section{Academic Motivation Questionnaire (AMQ)}

We assumed that a certain student's motivational profile related to a certain topic is an individual combination of features related to different SDT motivational orientations. Students cannot be labelled with a certain motivational orientation. The $\mathrm{AMQ}^{2}$ was employed in this research in order to distinguish students with different motivation orientations. It is based on the "Academic Self-Regulation Questionnaire" (SRQ-A) developed by Ryan and Connell (1989) and the "Academic Motivation Scale" (AMA) developed by Vallerand et al. (1992), both of which are based on SDT theory (Deci et al. 1994; Ryan et al. 1991). Three new items were designed for measuring amotivation through a deductive approach (Burisch 1984). Thus, the final instrument consisted of 29 items and assessed the participants' amotivation (4 items), external regulation (4 items), introjected regulation (4 items), identified regulation (5 items) and finally intrinsic motivation (12 items). The instrument was written in the native language of the participants and responses were provided on a sevenpoint Likert-type scale $(1=$ strongly disagree and $7=$ strongly agree $)$.

Students answered the AMQ before the teaching sequence. The aim of using the questionnaire was to examine their motivational orientation based on SDT. The student patterns do not automatically follow the categories that emerge from the theory, and therefore students' answers revealed a more detailed picture of their particular motivation orientations. Students may display features of more than one motivation orientation at the same time.

\section{Interviews}

Students who clearly had a higher mean score in one subscale compared with the others were selected for an interview. The selection is explicated in the "Results" section. The students were interviewed as individuals no more than 2 or 3 weeks after the teaching sequence had been

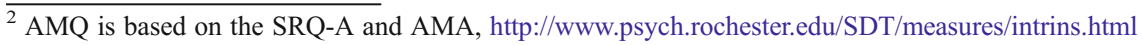


completed. The interviews were semi-structured, meaning that a general structure was set up by the interviewer who decided on the topics to be covered and the main questions to be asked prior to the interview. The detailed structure, meaning the order of the topics and additional clarifying working questions, was decided during the course of the interview, depending on what emerged from the responses of a particular interviewee. The interviewee had a freedom to decide how much to say and how to express it (e.g. Drewer 2003). The interviews were informal and conversational and were conducted in the mother tongue of the interviewee. The aim of the interviews was to reveal the students' view of the motivational features of the designed teaching sequence.

This research is concerned with students' motivation and the possibilities to enhance motivation by supporting the fulfilment of students' basic psychological needs and their interest. The questions were planned to adequately reflect the aims of the research and the variables to be measured (Cohen et al. 2007). The interview protocol (Appendix 1) was developed according to four motivational axes of the sequence: possibilities to influence the way things were done (support for autonomy), possibilities for collaboration with classmates (support for social relatedness), possibilities to feel competent during the learning tasks (support for competence) and support for interest (interesting content or context, feeling and value-related aspects of interest). The interview protocol started with asking students about their experiences and opinions about the designed teaching sequence generally. The following questions reflected the aspects related to the motivational features embodied in the sequence. When designing, the questions related to the motivational features phrases such as "students' feeling of autonomy will be supported..." were considered. However, it became obvious that students aged 14-15 cannot be asked about their feeling of autonomy using such difficult concepts, and therefore the questions were reformulated in order to be understood by students. The fulfilment of the students' need for autonomy for example was clarified by asking "What kinds of possibilities did you have to influence the way things were done during the site visit teaching sequence?". The fulfilment of their need for social relatedness, was clarified by asking for example "What kinds of possibilities to work together with your classmates did you have during the site visit teaching sequence?" The focus was on how students' reflected the fulfilment of their three basic psychological needs. The questions whose immediate response was yes or no were followed by question "why" or a request to explain their response in more detail.

The interviews were recorded, transcribed in full and then analysed. The analysis of the interviews followed the principles of theory-driven content analysis (Patton 2002; Tuomi and Sarajärvi 2002), as the categories for the analysis deductively emerged from the theory. According to the interview protocol, after a preliminary reading of the transcriptions, a theme was defined as a unit of analysis. Themes were related to the basic needs, and units of analysis were coded on the grounds of the basic need they illustrated. The coding followed the categorisation of basic needs and interest, such that AU (support for the need of autonomy), CO (support for the need of competence), SR (support for the need of social relatedness), FEE (support for feeling-related interest), VALUE (support for value-related interest), CON (support for content-related interest) and CNTX (support for context-related interest). The last four codes are aspects of interest and there were also more specific subcategories for the main categories.

The student interviews had a second part that was concerned with students' reflections on what they remembered about the content of the teaching sequence. The interview questions of this part reflected the intended learning outcomes and concerned materials seen during the visit, products that were manufactured of these materials and careers and professions that were related to the company. The results of that part are reported elsewhere. 
Table 1 Interview analysis categorisation

AU AU1 Active co-planning of a teaching unit (or a large learning activity) by students

AU2 Activities which support feeling of autonomy or situations where a student could make (alone) choices on how to perform alone (including use of ICT)

AU3 Activities which support feeling of autonomy or situations where students could make choices in a small group on how to perform in a small groups

AU4 Use of student-centred learning methods

$\mathrm{CO} \quad \mathrm{CO} 1$ Activities (alone) which support a feeling of competence or success in doing a task (including use of ICT) or tasks which are possible for the most students to solve or there are differentiation in the task according to students' abilities

CO2 Activities (in a small group) which support a feeling of competence or success in doing a task (including use of ICT)

$\mathrm{CO} 3$ Use of constructive evaluation methods (self and group evaluation)

SR SR1 Activities in a small groups which support feeling of social relatedness (feeling that students are successful team or feeling of being close to peers when working towards the goals of the activity) (including use of ICT)

SR2 Activities which support the feeling of trust and respect amongst peers

FEE FEE1 Activities which wake up curiosity

FEE2 Activities which hold attention

FEE3 Activities which are funny/enjoyable to do

VALUE VALUE1 Activities which wake up value-related components of interest, like activities with some value from the point of view of science learning (benefit) or future studies or career activities which support the feeling of the importance of working

VALUE2 Activities which value students' own ideas

CON CON1 Activities which support the feeling that properties of materials are an interesting content

CON2 Activities which support the feeling that learning science in a material science context is interesting

CNXT CNXT1 Interesting context

The interview transcripts were read several times. First, the interviewees' utterances were associated with the main category features mentioned above. Second, reduced expressions in English were composed after distinguishing the relevant issues from the ones focusing on something else and encoded with the relevant category code in the analysis table. Students' word-for-word quotations, the English translations of the word-for-word quotations and the coded reduced expressions of these quotations were arranged in the analysis table. Finally, it was checked that the categorisation is convergent with the original Finnish or Greek expression (Table 1).

\section{Results}

Comparison of Motivational and Interest-Related Characteristics of Science Learning Activities, in General and Designed Teaching Sequence

Sum variables for Finnish and Greek students were constructed based on the items for each of the five subscales of the ESIA Questionnaire for the ordinary science learning activities $\left(M_{1}\right)$ and for the designed teaching sequence $\left(M_{2}\right)$. The means and the standard deviations of the subscales in each country are presented in Table 2 . The students as groups were generally moderately positive (means $>4.5$ ) for both the ordinary science activities in general and the 
Table 2 Means and standard deviations for motivation subscales based on students' evaluations in each country and a comparison of motivational features of science activities in general and designed teaching sequences

\begin{tabular}{|c|c|c|c|c|c|c|c|}
\hline \multirow[t]{2}{*}{ Country } & \multirow[t]{2}{*}{$\begin{array}{l}\text { Motivational features of the } \\
\text { science activities in general } \\
\text { and designed teaching sequences }\end{array}$} & \multicolumn{2}{|c|}{$\begin{array}{l}\text { Science learning } \\
\text { activities in general }\end{array}$} & \multicolumn{2}{|c|}{$\begin{array}{l}\text { Designed } \\
\text { teaching } \\
\text { sequence }\end{array}$} & \multicolumn{2}{|c|}{ Difference } \\
\hline & & $M_{1}$ & $\mathrm{SD}_{1}$ & $M_{2}$ & $\mathrm{SD}_{2}$ & $M_{2}-M_{1}$ & $t$ \\
\hline \multirow[t]{5}{*}{ Finland $(N=27)$} & Perceived autonomy/choice (1) & 4.61 & 1.15 & 4.22 & 1.10 & -0.40 & $1.8^{\mathrm{ns}}$ \\
\hline & Perceived competence (2) & 4.60 & 1.23 & 4.63 & 0.79 & 0.03 & $0.2^{\mathrm{ns}}$ \\
\hline & Support for relatedness (3) & 4.70 & 1.09 & 4.49 & 0.86 & -0.21 & $1.4^{\mathrm{ns}}$ \\
\hline & Interest/enjoyment (4) & 4.44 & 1.25 & 4.31 & 1.00 & -0.13 & $0.7^{\mathrm{ns}}$ \\
\hline & Interest/value or usefulness (5) & 5.08 & 1.55 & 4.68 & 1.52 & -0.40 & $1.9^{\mathrm{ns}}$ \\
\hline \multirow[t]{5}{*}{ Greece $(N=27)$} & Perceived autonomy/choice (1) & 5.04 & 1.34 & 5.33 & 1.17 & 0.29 & $1.3^{\mathrm{ns}}$ \\
\hline & Perceived competence (2) & 5.08 & 1.20 & 5.27 & 1.20 & 0.19 & $1.0^{\mathrm{ns}}$ \\
\hline & Support for relatedness (3) & 4.57 & 1.29 & 4.62 & 1.29 & 0.05 & $0.3^{\mathrm{ns}}$ \\
\hline & Interest/enjoyment (4) & 5.00 & 1.80 & 5.67 & 1.20 & 0.67 & $3.0^{* *}$ \\
\hline & Interest/value or usefulness (5) & 5.18 & 1.90 & 5.35 & 1.64 & 0.17 & $1.2^{\mathrm{ns}}$ \\
\hline
\end{tabular}

Item examples in each subscale: (1) I do the activity because I want to; (2) I think I am pretty good at the activity; (3) I feel close to my peers during the activity; (4) I enjoy the activity very much; (5) I think doing the activity could help me learn science

${ }^{\mathrm{ns}} p>0.05 ; * * p<0.01$

designed teaching sequences in both countries. The paired-samples $t$ test between the motivational features of ordinary science learning activities and the designed teaching sequence $\left(M_{2}-M_{1}\right)$ revealed the subscale interest/enjoyment among the Greek students as the only significant positive difference $(t=3.005, d f=26, p=0.006)$. The power of the difference was tested using Cohen's $d\left(d=M_{2}-M_{1} / \mathrm{SD}\right.$ pooled, where SD pooled=square root $\left[\left(\mathrm{SD}_{1}{ }^{2}+\mathrm{SD}_{2}{ }^{2}\right) / 2\right]$ (Cohen 1988), which was 0.49 (small). Cohen's $d$ measures the effect size for the difference: no effect at $d<0.2$, small effect at $0.2 \leq d<0.5$, moderate effect at $0.5 \leq d<0.8$ and large effect at $d \geq 0.8$. The Greek students as a group found the designed teaching sequence more interesting and enjoyable than their ordinary science activities. Although only a subscale of the ESIAQ showed a significant positive difference, more interesting aspects were revealed in the interviews of individual students. These results are presented in the next paragraphs.

\section{Students' Views of the Motivating Features of the Designed Teaching Sequence}

SDT assumes differences in the motivational profiles of individuals. In this research, we wanted to interview students with different motivational profiles. Students' mean scores of each subscale were counted. We then tracked students that had high score in one subscale and lower scores in others, and assumed that the higher mean score might reflect their motivational orientation towards the topic. Students that had a clear "peak" in their profile usually had a high mean score in the subscale amotivation. In the Finnish sample, it was not possible to distinguish the category introjected regulation because if a student had high score in that category he or she always had an even higher mean score in some other category. Furthermore, a combination of high scores in the categories external regulation and identified regulation was common in both samples (for example students F_10 and GR_19). 
Table 3 Subscale mean scores of the selected participants

\begin{tabular}{clllll}
\hline Participants & Amotivation & $\begin{array}{l}\text { External } \\
\text { Regulation }\end{array}$ & $\begin{array}{l}\text { Introjected } \\
\text { Regulation }\end{array}$ & $\begin{array}{l}\text { Identified } \\
\text { Regulation }\end{array}$ & $\begin{array}{l}\text { Intrinsic } \\
\text { Motivation }\end{array}$ \\
\hline Finnish & & & & & \\
F_02 & $\mathbf{5 . 0 0}$ & 2.75 & 3.00 & 2.25 & 1.92 \\
F_05 & 1.50 & $\mathbf{3 . 7 5}$ & 1.75 & 2.40 & 2.25 \\
F_10 & 1.25 & 5.75 & 4.50 & $\mathbf{6 . 2 0}$ & 3.75 \\
F_09 & 1.00 & 3.00 & 2.75 & $\mathbf{5 . 0 0}$ & 4.42 \\
F_04 & 1.25 & 2.75 & 2.25 & 4.20 & $\mathbf{4 . 4 2}$ \\
Greek & & & & & 5.92 \\
GR_01 & 1.20 & 3.67 & 3.75 & $\mathbf{6 . 0 0}$ & 4.08 \\
GR_12 & 3.80 & 4.33 & $\mathbf{6 . 0 0}$ & 4.75 & 5.17 \\
GR_19 & 1.20 & $\mathbf{6 . 0 0}$ & 4.00 & 5.25 & $\mathbf{5 . 5 0}$ \\
GR_23 & 1.00 & 1.00 & 1.00 & 4.00 & 1.00 \\
GR_25 & $\mathbf{3 . 4 0}$ & 2.00 & 1.75 & 1.00 & \\
\hline
\end{tabular}

Bolded numbers show the highest mean score. Italicised numbers show the high mean in another subscale

Another common combination of high scores was found in subscales identified regulation and intrinsic motivation (for example students F_09, F_04, GR_01 and GR_23). This may imply that students have adopted the aims of school science either because of extrinsic reasons or because they are intrinsically interested in the topic. High mean scores only in the category intrinsic motivation were difficult to find. This is also reasonable because aims of studying do not emerge from the students but from the curriculum. Students who most clearly had a high score in one subscale compared with other subscales were selected for an interview. Besides the mean scores, practical reasons somewhat guided the selection. The interviews were conducted during the school day, and if someone was absent, he or she could not be interviewed. In order to strengthen and verify our selection, Table 3 presents the means of each selected student in the five subscales. Following the above procedure, ten (five Finnish and five Greek) students were selected for the interviews.

The analysis was conducted from the perspective of the motivational conjectures embodied in the design, that is, the features of the design intended to support feelings of autonomy, social relatedness and competence.

\section{Support for the Feeling of Autonomy}

A Greek student with a high score on the subscale external regulation (GR_19) emphasised the need for autonomy ("We found all the information alone (i.e. the students; without teachers being involved), all the experiments, and the conclusions were, our own conclusions"). This student increased her self-determination and fulfilled her need for autonomy from her teachers' authority, competence and relatedness by decreasing her levels of anxiety and diminishing the avoidance of failure that no longer had any meaning. A Finnish student with a relatively high mean score on the external regulation subscale (F_5) appreciated the possibility to make decisions related to writing an article, but he also said that working in an independent way is more difficult than working according to the teacher's instructions (Table 1).

A Finnish student with high mean scores on the identified and external regulation subscales $\left(F_{-} 10\right)$ value the possibility to choose the focus of the reporting task and who to 
work with, and would have appreciated even more possibilities to make decisions about studying. The Greek and Finnish students with high mean score on the subscale identified regulation (GR-01) and (FN_09) both stressed the value of the sequence for fulfilment of their need for autonomy, and its help for enhancing their interest in science. The Greek (GR_01) student stated: "we could do the experiments alone (i.e. without our teacher's supervision) and find the answers ... thus the learning is not only theories, we saw some theoretical issues in actual practice, and this enhanced our interest ...". Similarly, the Finnish (FN_09) student stressed "....well in principle when you had the kind of feeling that the tasks weren't just put in front of you and you just have to do them, but that you had the possibility to influence what you are about to do ...".

The Greek participant $\left(\mathrm{G}_{2} 23\right)$ with a high mean score on the subscale intrinsic motivation emphasised the fulfilment of the need for autonomy ("Everyone said his/her opinion, we searched for information over the Internet, and everyone added information and it was possible to combine his/her knowledge with all the others so, to be more comprehensive to our classmates... and the answer was constructed step by step... usually, the teachers alone decide what students should learn and students are stressed a lot when they have to follow what is being taught. When students decide together with their teachers, they feel more comfortable and there is no stress").

\section{Support for the Feeling of Competence}

The Greek student with a relatively high mean score on the subscale amotivation (GR_25) stressed that she enhanced her self-competence. She said, "In the past, I was not interested to read, I was afraid of physics, I believed that to try with physics was a waste of time, that I couldn't be effective, but now I have more self-confidence and I can more easily approach the subject". A by-product of a low self-competence may be the isolation of the group of students who are highly motivated to do a particular activity. In our case, both groups had members with a high interest towards physics. The sequence also gave those with high amotivation scores a chance to be members of a group and fulfil their need for relatedness and self-competence.

The designed teaching sequence helped the Greek student with a high score on the subscale external regulation (GR_19) to enhance her feeling of competence and abandon her fear of failure. As she stated: "I liked very much the fact that we were well prepared before our visit ... I was not anxious that I did not know something..." The same student justified her judgments about the benefits of the sequence to the fulfilment of her need for competence ("If you feel well you do have more interest for something even strange and new that you learn..."). A Finnish student with a relatively high mean score on the external regulation subscale (F_5) felt more competent when he noticed he understood something. He was satisfied with himself for choosing a topic for his article because it seemed interesting and it was not a commonly selected topic. In the student's opinion, it was interesting to write the article about a topic that he was not familiar with prior to participating in the designed teaching sequence.

A Greek participant with a high mean score on the subscale introjected regulation (GR_12) connected her experience within the sequence with her self-esteem. She referred to her high self-esteem as a result of the preparation "we (all students) were better prepared, we knew the procedure, how to speak, we were working altogether, we had prepared the questions and what everyone should do, we were better prepared, I enjoyed working in groups to search for information on the Internet and we did experiments...". 
The Finnish student with a high mean scores on identified and extrinsic regulation subscales (F_10) said that he felt that he had succeeded with the tasks related to the sequence. He also valued the positive feedback that he received from the teacher and believed that the success could also influence the marks he would achieve for this course.

\section{Support for the Feeling of Social Relatedness}

A Greek student with a relatively high mean score on the subscale amotivation (GR_25) stressed her chance to be a member of a group "I was not friends with the others in the group, and we become more close and we developed a cooperation ... it was very nice that we were working altogether and we challenged our abilities...". Similarly, a Finnish (FN_2) student with a relatively high mean score on the subscale amotivation enjoyed working with her classmates, and she felt that cooperation was a very valuable thing that enriched studying. She put it thus "well because when all the people have like different opinions about issues of what they prefer, and then when you combine them then it will be one big surprise box or such a thing from which you get all kinds of bursts of motivation and so on...".

The sequence helped a Greek student with a high score on the subscale external regulation (GR_19) also to fulfil her need for relatedness ("Working in groups it was very interesting because I had the opportunity to work with my classmates that I had never been so close to and to know some of their aspects that I had never known. The sequence helped me to establish new personal relationships...").

The Greek participant with a high mean score on the subscale introjected regulation (GR_12) stressed the fulfilment of the need for relatedness ("One of the most important things was that we were working in groups and they gave us some materials and allowed us to experiment in the groups. Thus, we had the opportunity to be closer to our classmates, we had a cooperation ... This is an important way to find and give help, to discuss and finally to learn more..."). In other words, she mentioned the utility value of working in groups (need for relatedness) that was also related to the need for group autonomy (formulating questions within the group) that helped her to be better prepared (need for competence) and, finally, to be more interested and willing to learn.

The Greek and Finnish students with high mean scores on the subscale identified regulation (GR-01) and (FN_09) stressed the value for enhancement of their personal relationships and fulfilment of their need for relatedness. The Greek student said "We learned to co-operate with other classmates, to fill the others' blanks, and thus it was better in the lesson, to work in groups and not to be egoists. I am more cooperative than before now, I learned to share information and things ... I was not so before the project ..." while the Finnish student said: “... especially that of course there are like friends and familiar people, so that made it easier, but also that when you study it kind of felt more effective because you had a good group so you also shared the aims and so on ...".

The Greek participant (G_23) with a high mean score on the subscale intrinsic motivation emphasised cooperative learning ("I was interested in physics before, because I like physics very much. However, the cooperative learning urged/motivated me further ... we had in the class some other students that were not interested at all in physics, but this approach facilitated their efforts and they were urged to learn more topics ..."). Furthermore, she stressed the fulfilment of her need for relatedness ("I had the opportunity to cooperate with some classmates who, otherwise I would personally never be engaged with... we did not have good relationships but, through the projects, we developed better personal relationships ...cooperation helps all ...”). 


\section{Support for Interest}

In their interviews, both the participants with relatively high mean scores on amotivation perceived the sequence as being more interesting than ordinary teaching. The Finnish student with a high mean score on the subscale amotivation (FN_2) said: "before this [the visit sequence]...for me it was important only to have paper in the store so that I could draw and so on but then when you start to think about the fact that there are so many phases when they do things, so of course it is interesting how they manage and how it is done, what are the processes ...". Additionally, the Greek student with a high mean score on the subscale amotivation (GR_25) said: "(in contrast to the ordinary lesson) I very much liked the experiments because we learned a lot of new interesting things".

The Greek participant with a high mean score on the subscale introjected regulation (GR_12) stressed the interest enhancement ("the (sequence) was very important because students are more interested, there is more of a will for learning ...")

The Finnish student with high mean scores on identified and extrinsic regulation subscales (F_10) found the designed teaching sequence more interesting compared to studying at school. He emphasised the value-related side of interest, as he said "first I did not find science studying very important but now when I saw where one could get by studying science...".

The Greek student with a high mean score on the subscale identified regulation (GR-01) stated: "The visit was very important because we saw very important materials that we had not seen before, and we understood better how it happens when we speak with others via telephone lines and that this is more complicated than it seems to be, ... we learned so many simple and important things about the information transfer, a technology that we use every day without understanding how it happens, and now this project helped us to understand better both the theory and the reality...". Similarly, the Finnish student with a high mean score on the subscale identified regulation (FN_09) stated: "I have somehow liked studying physics and chemistry so it has not like at least made worse, well somehow it increased interest ... well then from another point of view at the company when you chatted with those people it was just the action and how specific everything was...".

The Greek participant ( $G \_23$ ) with a high mean score on the subscale intrinsic motivation acknowledged that she was motivated towards physics before. However, she emphasised that the sequence helped her personally enhance her motivation and interest through acquiring new knowledge ("It was a very interesting experience, we learned a lot of new issues, we did experiments..."). She also mentioned the content of the new materials ("The fibre glasses weld was the most interesting thing we learned"). The Finnish student with high mean score on the subscale intrinsic motivation (F_04) stressed the significance of the authentic context, as she said: "well if you heard about this at school it would not have been so interesting, but now when you were first told what kind of place it is and then you saw it yourself, the whole thing was interesting."

\section{Discussion}

\section{The Effect of the Designed Teaching Sequence on Students' Motivation}

Quantitative measures with the ESIA Questionnaire showed that, despite our efforts with the designed teaching sequence, students did not significantly experience enhanced perceived autonomy/choice, competence, support for relatedness, interest/enjoyment (except the Greek students who reported more interest and enjoyment within the designed teaching sequence) and interest/value or usefulness. This result can be interpreted in three ways. 
First, the result may have occurred due to the short duration of the sequence (the designed sequence constituted of five units) compared with the whole school year for example, denoting that such short-term interventions cannot generate permanent changes in students' motivation and interest (see Lott 2003, for similar evidence). Laursen et al. (2007), after reviewing several papers considering the effects of shortterm interventions, argue that despite the popularity of the short-term intervention model, there is little convincing research literature about its statistically significant effectiveness (p. 50), further short duration interventions cause mainly affective outcomes, as participants usually enjoy these occasions. Indeed, the only significant difference $(p<0.05)$ was depicted in the Greek students' perceived "interest/enjoyment". Why then did Finnish students not perceive the expected enhancement of their interest and enjoyment? Finnish students are more used to this way of working, as it is recommended in the Finnish National Core Curriculum (NCCBE 2004), and there has been a tradition for over 20 years of organising site visits in Finland (Kuitunen and Meisalo 1988). In contrast, it was rather a novel and unprecedented way of studying in the Greek educational context where visits are usually planed to archaeological sites rather than to science related or industrial sites and the collaborative jigsaw method was also new to them. Thus, the students thought that the experience was fascinating. In any case, the question remains: What is a sufficiently long intervention to enhance students' motivation?

Secondly, the original IMI questionnaire was developed for experimental settings that were clearly restricted from other activities. In our case, however, the border between the sequence and ordinary teaching was blurred, as the sequence was intended to have a fixed connection with the curriculum. Students may have had some difficulty, despite our efforts, differentiating between ordinary teaching and the sequence.

Thirdly, the results can be explained on the basis of the inappropriateness of the ESIA Questionnaire for identifying slight differences between the designed teaching sequence and ordinary teaching. For instance, a ceiling effect was observed in some subscales. Students with high scores (5-7) in the pre-visit questionnaire could not place themselves higher after the implementation, and thus a noticeable difference is visible only in the answers of students who had low scores in their preimplementation questionnaire, in this case those with high scores on the amotivation subscale. However, as happens in most intervention studies (see Martin 2004), the sample of the study was quite small and students with high scores on certain subscale were represented unequally. Students with high scores on the amotivation subscale represented only a small portion of the whole sample (4/27 Greek students and 3/27 Finnish students). Alternatively, the initial ceiling effect might have occurred because the students were probably very motivated when answering the questionnaire the first time, as it felt special to be involved in an educational experiment. In contrast, after the intervention, they were not so happy when they realised that the same procedure of filling the questionnaire was about to be conducted again, and the task started to feel boring.

\section{Students with Different Motivational Profiles}

It is important that all students, despite their motivational profile, feel some personal relevance when participating in science classes, and this also concerns those students who do not see themselves potentially pursuing a career in the field of science and technology in the future. This is why we considered it important to design a teaching sequence with 
motivational features that would appeal to students with a variety of the motivational profiles, not only those who were already highly motivated.

Beyond the methodological issues that have arisen from the ESIA Questionnaire, the analysis of the qualitative data revealed important evidence in support of motivational theories. Specifically, the subscale means of the participants are worth considering. Students with high scores on amotivation subscale usually scored lower in both extrinsic and intrinsic motivation, and that part of the AMQ data can be clearly interpreted. However, it is remarkable that other participants usually had high mean scores on more than one subscale of extrinsic and/or intrinsic motivations (see the numbers in italics, Table 2). This is in line with the arguments of Lee et al. (2010), as they argue that these two can co-exist and should be dichotomized as two goals rather than to examine them as lying on a continuum of a single motivational force as the SDT asserts (see Deci and Ryan 2000). Moreover, it is evident that differently regulated orientations may co-exist within the same individual, although one is prominent.

Although hardly any significant effects were identified in the questionnaire data, some aspects became salient with the interviews. All embodied conjectures (support for autonomy, support for competence, support for the feeling of social relatedness and support for interest) were perceived by the students. The most important evidence from our project emerged from the qualitative data that showed that students with different motivational profiles found different aspects of the sequence appealing and important.

The interest-related conjectures, namely the content and context, and the feeling- and value-related aspects of these were most commonly mentioned aspects of the designed teaching sequence mentioned by the students, despite their motivational profile. Valuerelated aspects are for example recognising the connection between science studies and future career possibilities, meeting real people behind job descriptions and speaking with them, and identifying how topics studied at school applied in a real setting. Students mentioned that they appreciated the opportunity to see the future value of their science studies, in other words what possible career choices they had. It can be argued that recognising this connection may enhance the feeling of relevance of studying science, and this concerns especially those with high scores on the subscale amotivation and low mean scores on other subscales. This is in line with the results presented by Hulleman and Harackiewicz (2009), as they argue that encouraging students to make connections between science course material and their lives enhanced both interest and performance for students with low success expectancies. Emphasising the feeling-related valence of interest related to the designed teaching sequence was also common for students despite their motivational orientation, even though the positive feelings were not necessarily connected with the science side of the visit, but in some cases with the snack and soda service offered to the students.

Other motivational conjecture perceived with students despite their motivational profile was the support for the feeling of social relatedness. It may be the new context that made the students feel closer to each other, or that they had an interesting enough task (interviewing experts in the site) that was probably quite challenging that may have promoted their feeling that they shared a common aim worth pursuing. From the point of view of the support for the feeling of competence, two Greek students mentioned the importance of careful preparation before the visit. This is in line with the arguments of Storksdieck (2001), as he argues that the student preparation phase, examining the students' prior knowledge and attitudes, and a follow-up are essential to successfully connect the visit to the curriculum. The students with relatively high scores on the autonomous motivation subscales were happy to share their already existing interest towards the topic, and the tasks related to it with their group members. 
Neither the Greek nor the Finnish interviewed students with high mean scores on the amotivation subscale mentioned anything relevant to their need for autonomy or selfdetermination. Also, those with high scores on external regulation subscales were satisfied with the idea that the teacher is the one who decides which aspects aspects of a course are worth studying. An interesting aspect, however, was that the Greek student with high score in external regulation perceived the sequence positively because it broke the everyday routine and saved them from their teacher's strict supervision. Within ordinary teaching, while regulating their behaviour to external demands, students usually experience high levels of anxiety and fear of failure, experiences that threaten both their need for autonomy and their need for competence (Johnston and Finney 2010, p. 293). This student found the aspects that helped them resolve their anxiety important (within the supportive atmosphere of the group, students do not need to fear failure so much) and thus improved their competence and fulfilled their need for relatedness. After the designed teaching sequence, she found that the new teaching environment helped her to abandon these feelings and fears. Even the autonomy the sequence provided her was interpreted as abandonment by the teachers who created stressful conditions. The higher the scores on the more autonomous regulatory styles were, the more the students valued the designed teaching sequence, with respect to the autonomy they experienced and the value of the activity per se. Offered autonomy was most clearly perceived by the students with high mean scores on autonomous regulatory styles, namely identified and intrinsic orientations. These students appreciated the autonomy offered to them and considered it essential for their motivation. We suppose it would not be too difficult to increase students' decision power in smaller or larger aspects of studying, and it might be very useful from the students' motivation point of view.

\section{Conclusions}

In this research, we designed a site visit teaching sequence for science education. The selfdetermination theory (e.g. Ryan and Deci 2002)-based conjectures about possibilities to enhance motivation by supporting students' innate psychological needs were embodied in the design. The aim of the sequence was to enable lower secondary school students to enhance their motivation towards science learning. A certain teaching sequence may be experienced in various ways, depending on the motivational orientation of the receiver. Therefore, we were interested in examining how the motivational features appeared to students with a variety of motivational profiles.

The aim of this research was to examine the embodied motivational conjectures of the design. These conjectures aimed to fulfil students' basic psychological needs. Although we realise that the three basic psychological needs are universal, we strongly support the idea that they have a different strength and keenness for satisfaction. Prior experiences from the individuals' engagement in similar activities create a subjective-specific motivational orientation towards various activities and domains. Each motivational orientation results from a different degree of satisfaction of the three basic psychological needs. That is, each time individuals start a new activity they have a subjective estimation or a bias of what psychological needs might be satisfied by the activity. This bias makes individuals sensitive to some activities and not to others.

What our participants stressed in the interview is that they found aspects in the designed teaching sequence that fulfilled their basic psychological needs. Our evidence extends our knowledge of how out-of-school visits in the context of science education should be designed and organised, and what aspects should be taken into account in order to enhance motivation towards the topic. We conclude that a carefully designed site visit teaching 
sequence that encompasses support for students' basic psychological needs and their interest is a reasonable way of enhancing students' motivation towards a topic. Different students value aspects intended to enhance motivation differently, and therefore various motivational features make it easier to affect different students with one sequence.

We implemented the sequence in Finland and in Greece. Our conclusion is based on evidence from two samples with different teaching traditions and different achievement results on international surveys. Despite these differences, the similarities that were revealed in the interviews further strengthens our conclusion. This conclusion suggests that a science course (and courses of other subject matters) should be organised not only taking into account students' prior knowledge but also students biases for which basic psychological needs they want fulfilled and at which level the course could fulfil them. These biases mediate students interest and the extent to which different activities interest them. Brophy (2008) suggests shifting from focusing on intrinsic motivation to focusing on how to motivate students to learn, i.e. to find learning activities meaningful and worthwhile even though they do not necessarily feel pleasurable per se for the students. Our conclusions are in agreement with Brophy's (2008) and provide further evidence that, independent of context or country, students are learning science, based on what they view as meaningful and worthwhile activities. As the basic psychological needs of students in a class may vary or even be well hidden, it is important to organise rich teaching settings to enable each student to experience teaching in a way that is compatible to his or her personal needs, so that each student can find at least one reason to be actively involved in and enjoy the teaching. As classes are organised on the basis of age and students with different motivational orientations are involved, instruction should take into consideration the different motivational orientations in the class and the different motivational needs that students may have.

\section{Appendix 1. Interview Questions}

Semi-structured interview, questions

Guided questions or themes discussed with the students during the interview.

0. Orientation

Can you please tell me about the site visit and the learning tasks related to it.

1. What was most interesting or motivating in the site visit teaching sequence?

What else was interesting or motivating?

Ask about the following features of the site visit if the student does not mention anything about them.

2. What kinds of possibilities did you have to influence the way things were done during the site visit teaching sequence?

Was it interesting or motivating to have an influence on the way things were done during the site visit teaching sequence?

Did you have possibilities to plan the learning activities?

Did you have an influence on the way the learning tasks were done?

Did you have an influence on choosing the learning tasks?

Did you have an influence on the order the learning tasks were done?

What else were you allowed to decide about?

Was it nice to influence the way things were done during the site visit teaching sequence? 
3. What kinds of possibilities to work together with your classmates did you have during the site visit teaching sequence?

Did working together with your classmates increase your motivation or interest towards studying?

Did you feel close to your group members?

Was it nice to work together with the other pupils?

Did you have a possibility to plan the learning activities with the other pupils?

4. Did you feel competent during the learning tasks related to the site visit teaching sequence?

Are you sure you were competent?

Did feeling competent increase your interest or motivation towards studying?

What made you feel yourself competent? Was it your own, your teacher's or other pupils' view?)

Did you feel competent during the ICT tasks related to the site visit teaching sequence?

Did you feel your competency was appreciated?

Could you do well some other thing related to the site visit teaching sequence?

5. Can you please tell me about your feeling of interest and enjoyment during the site visit teaching sequence.

Did you feel convenient during the learning tasks related to the site visit teaching sequence?

Did your feeling of interest and enjoyment have an influence on your interest and motivation towards the site visit teaching sequence?

What learning tasks affected your interest most during the site visit teaching sequence?

6. Can you please tell me about the motivating or interesting content or context of the site visit teaching sequence.

7. Overall, what do you think about the site visit teaching sequence?

\section{References}

Brislin, R. W. (1986). The wording and translation of research instruments. In W. J. Lonner \& J. W. Berry (Eds.), Field methods in educational research (pp. 137-164). Newbury Park: Sage.

Brophy, J. (2008). Developing students' appreciation for what is taught in School. Educational Psychologist, 43(3), 132-141.

Burisch, M. (1984). Approaches to personality inventory construction. A comparison of merits. American Psychologist, 39, 214-227.

Cohen, J. (1988). Statistical power analysis for the behavioral sciences (2nd ed.). Hillsdale: Lawrence Earlbaum.

Cohen, L., Manion, L., \& Morrison, K. (2007). Research methods in education (6th ed.). London: Routledge.

Deci, E. L., \& Ryan, R. M. (2000). The "what" and "why" of goal pursuits: human needs and selfdetermination of behavior. Psychological Inquiry, 11, 227-268.

Deci, E. L., Eghrari, H., Patrick, B. C., \& Leone, D. (1994). Facilitating internalization: the self-determination theory perspective. Journal of Personality, 62, 119-142.

Design-Based Research Collective. (2003). Design-Based Research: an emerging paradigm for educational inquiry. Educational Researcher, 32(1), 5-8.

Drewer, E. (2003). Using semi-structured Interviews in small-scale research: a teacher's guide (Revised Ed.) Edinburgh: Scottish Council for Research in Education.

EU (2004). Europe needs more scientists! High level group on increasing human resources for science and technology in Europe. Available at http://ec.europa.eu/research/press/2004/pr0204en.cfm. Accessed 10 Apr 2010. 
EU (2005). Europeans, science and technology. Eurobarometer 224. Brussels: The Directorate General Press and Communication of the European Commission. Available at http://ec.europa.eu/public_opinion/ archives/ebs/ebs_224 report en.pdf. Accessed 17 Nov 2007.

Guay, F., Ratelle, C., \& Chanal, J. (2008). Optimal learning in optimal contexts: the role of self-determination in education. Canadian Psychology, 49(3), 233-240.

Hidi, S., \& Renninger, A. (2006). The four-phase model of interest development. Educational Psychologist, 41(2), 111-127.

Hulleman, C. S., \& Harackiewicz, J. M. (2009). Promoting interest and performance in high school science classes. Science, 326, 1410-1412.

Johnston, M., \& Finney, S. (2010). Measuring basic needs satisfaction: evaluating previous research and conducting new psychometric evaluations of the Basic Needs Satisfaction in General Scale. Contemporary Educational Psychology, 35(4), 280-296.

Juuti, K., \& Lavonen, J. (2006). Design-based research in science education: one step towards methodology. Nordina, 42(2), 54-68.

Juuti, K., Lavonen, J., Aksela, M., \& Meisalo, V. (2009). Adoption of ICT in Science Education: a case study of communication channels in a teachers' professional development project. Eurasia Journal of Mathematics, Science \& Technology Education, 5(2), 103-118.

Kuitunen, H., \& Meisalo, V. (1988). Science and technology education and industry. In C. Layton (Ed.), Innovations in science and technology education 2 (pp. 141-154). Paris: UNESCO.

Laursen, S., Liston, C., Thiry, H., \& Graf, J. (2007). What good is a scientist in the classroom? Participant outcomes and program design features for a short-duration science outreach intervention in K-12 classrooms. Life Sciences Education, 6, 49-64.

Lavigne, G. L., Vallerand, R. J., \& Miquelon, P. (2007). A motivational model of persistence in science education: a self-determination theory approach. European Journal of Psychology of Education, 22(3), 351-369.

Lavonen, J., Jauhiainen, J., Koponen, I., \& Kurki-Suonio, K. (2004). Effect of a long term in-service training program on teachers' beliefs about the role of experiments in physics education. International Journal of Science Education, 26(3), 309-328.

Lavonen, J., Juuti, K., Aksela, M., \& Meisalo, V. (2006). A professional development project for improving the use of ICT in science teaching. Technology, Pedagogy and Education, 15(2), 159-174.

Lavonen, J., Gedrovics, J., Byman, R., Meisalo, V., Juuti, K., \& Uitto, A. (2008). Students' motivational orientations and career choice in science and technology: a survey in Finland and Latvia. Journal of Baltic Science Education, 7(2), 86-103.

Lee, J. Q., McInerney, D. M., Liem, G. A. D., \& Ortiga, Y. P. (2010). The relationship between future goals and achievement goal orientations: an intrinsic-extrinsic motivation perspective. Contemporary Educational Psychology, 35(4), 264-279.

Lott, K. H. (2003). Evaluation of a statewide science inservice and outreach program: teacher and student outcomes. Journal of Science Education and Technology, 12(1), 65-71.

Martin, L. (2004). An emerging research framework for studying informal learning and schools. Science Education, 88, 71-82.

Minner, D., Levy, A., \& Century, J. (2010). Inquiry-based science instruction - what is it and does it matter... Journal of Research in Science Teaching, 47, 474-496.

NCCBE (2004). http://www.oph.fi/english/sources_of_information/core_curricula_and_qualification_requirements/ basic_education. Accessed 19 June 2012

Niemiec, C. P., \& Ryan, R. M. (2009). Autonomy, competence, and relatedness in the classroom. Theory and Research in Education, 7(2), 133-144.

OECD (2008). Encouraging student interest in science and technology studies: Global Science Forum. Paris: OECD.

Osborne, J. (2008). Engaging young people with science: does science education need a new vision? School Science Review, 89(328), 67-74.

Osborne, J., Simon, S., \& Collins, S. (2003). Attitude towards science: a review of the literature and its implications. International Journal of Science Education, 25(9), 1049-1079.

Patton, M. Q. (2002). Qualitative research \& evaluation methods (3rd ed.). Thousand Oaks: Sage.

Pintrich, P. R. (2003). A motivational science perspective on the role of student motivation in learning and teaching contexts. Journal of Educational Psychology, 95(4), 667-686.

Reeve, J., \& Halusic, M. (2009). How K-12 teachers can put self-determination theory principles into practice. Theory and Research in Education, 7(2), 145-154.

Ryan, R. M. (1982). Control and information in the intrapersonal sphere: An extension of cognitive evaluation theory. Journal of Personality and Social Psychology, 43, 450-461.

Ryan, R. M., \& Connell, J. P. (1989). Perceived locus of causality and internalization: examining reasons for acting in two domains. Journal of Personality and Social Psychology, 57, 749-761. 
Ryan, R. M., \& Deci, E. L. (2002). An overview of self-determination theory: an organismic-dialectical perspective. In E. L. Deci \& R. M. Ryan (Eds.), Handbook of self-determination research (pp. 3-33). Rochester: The University of Rochester Press.

Ryan, R. M., \& Deci, E. L. (2009). Promoting self-determined school engagement. In K. R. Wentzel \& A. Wigfield (Eds.), Handbook of motivation at school. New York: Taylor \& Francis.

Ryan, R. M., Koestner, R., \& Deci, E. L. (1991). Varied forms of persistence: when free-choice behavior is not intrinsically motivated. Motivation and Emotion, 15, 185-205.

Sandoval, W. (2004). Developing learning theory by refining conjectures embodied in educational designs. Educational Psychologist, 39(4), 213-223.

Sandoval, W. (2013). Conjecture mapping: an approach to systematic educational design research. The Journal of the Learning Sciences, 1-19.

Scherz, Z., \& Oren, M. (2006). How to change students' images of science and technology. Science Education, 90(6), 965-985.

Schiefele, U. (1999). Interest and learning from text. Scientific Studies of Reading, 3, 257-279.

Silvia, P. J. (2008). Interest-the curious emotion. Current Directions in Psychological Science, 17, 57-60.

Storksdieck, M. (2001). Differences in teachers' and students' museum field-trip experiences. Visitor Studies Today! 4(1), 8-12.

Tuomi, J., \& Sarajärvi, A. (2002). Laadullinen tutkimus ja sisällönanalyysi. Jyväskylä: Tammi.

Tytler, R., Osborne, J., Williams, G., Tytler, K., \& Cripps C.J. (2008). Opening up pathways: engagement in STEM across the primary-secondary school transition. Canberra: Australian Department of Education, Employment and Workplace Relations. Available at http:/www.dest.gov.au/sectors/career_development/ publications_resources/profiles/Opening_Up_Pathways.htm\#authors. Accessed 2 July 2009

Tytler, R., Symington, D., \& Smith, C. (2010). A curriculum innovation framework for science, technology and mathematics education. Research in Science Education, 41(1), 19-38.

Vallerand, R. J., Pelletier, L. G., Blais, M. B., Brière, N. M., Senécal, C. B., \& Vallières, E. F. (1992). The academic motivation scale: measure of intrinsic, extrinsic, and motivation in education. Educational and Psychological Measurements, 52, 1003-1017.

Vansteenkiste, M, Williams, G. C. \& Resnicow, K. (2012). Toward systematic integration between SelfDetermination Theory and Motivational Interviewing as examples of top-down and bottom-up intervention development: autonomy or volition as a fundamental theoretical principle. International Journal of Behavioral Nutrition and Physical Activity, 9:23. doi:10.1186/1479-5868-9-23.

Vasalampi, K., Salmela-Aro, K., \& Nurmi, J.-E. (2009). Adolescents' self-concordance, school engagement, and burnout predict their educational trajectories. European Psychologist, 14(4), 332-341.

Woolnough, B. E. (1996). Changing pupils' attitudes to careers in science. Physics Education, 31(5), 301308. 